\title{
DROSHA targets its own transcript to modulate alternative splicing
}

\author{
DOOYOUNG LEE, ${ }^{1}$ JIN-WU NAM, ${ }^{2}$ and CHANSEOK SHIN ${ }^{1,3,4}$ \\ ${ }^{1}$ Department of Agricultural Biotechnology, Seoul National University, Seoul 08826, Republic of Korea \\ ${ }^{2}$ Department of Life Science, Hanyang University, Seoul 04763, Republic of Korea \\ ${ }^{3}$ Research Institute of Agriculture and Life Sciences, Seoul National University, Seoul 08826, Republic of Korea \\ ${ }^{4}$ Plant Genomics and Breeding Institute, Seoul National University, Seoul 08826, Republic of Korea
}

\begin{abstract}
The nuclear RNase III enzyme DROSHA interacts with its cofactor DGCR8 to form the Microprocessor complex, which initiates microRNA (miRNA) maturation by cleaving hairpin structures embedded in primary transcripts. Apart from its central role in the biogenesis of miRNAs, DROSHA is also known to recognize and cleave miRNA-like hairpins in a subset of transcripts without apparent small RNA production. Here, we report that the human DROSHA transcript is one such noncanonical target of DROSHA. Mammalian DROSHA genes have evolved a conserved hairpin structure spanning a specific exon-intron junction, which serves as a substrate for the Microprocessor in human cells but not in murine cells. We show that it is this hairpin element that decides whether the overlapping exon is alternatively or constitutively spliced. We further demonstrate that DROSHA promotes skipping of the overlapping exon in human cells independently of its cleavage function. Our findings add to the expanding list of noncanonical DROSHA functions.
\end{abstract}

Keywords: DROSHA; Microprocessor; alternative splicing

\section{INTRODUCTION}

MicroRNAs (miRNAs) are a class of small regulatory RNAs of $\sim 22$ nucleotides $(\mathrm{nt})$ involved in diverse biological pathways in bilateral animals. As key regulators of gene expression, they pair with complementary sites within mRNAs and direct post-transcriptional repression of those messages (Bartel 2009). Aberrant miRNA expression is associated with various human diseases, including cancer (Lujambio and Lowe 2012), highlighting the importance of these tiny regulators.

Much is now known about how miRNAs are generated in cells (Ha and Kim 2014). In the canonical biogenesis pathway, miRNA genes are transcribed as primary miRNAs (pri-miRNAs) containing one or more characteristic hairpin structures. These miRNA hairpins are recognized and cleaved by the nuclear Microprocessor complex, a heterotrimeric complex consisting of one molecule of DROSHA, an RNase III, and two molecules of its essential cofactor DiGeorge syndrome critical region 8 (DGCR8), to release $\sim 60$ - to 80 -nt precursor miRNAs (pre-miRNAs) (Lee et al. 2003; Denli et al. 2004; Gregory et al. 2004; Han et al. 2006; Nguyen et al. 2015; Kwon et al. 2016). Pre-miRNAs are then exported to the cytoplasm and further processed by a second RNase III, DICER, producing 22-base pair

Corresponding author: cshin@snu.ac.kr

Article is online at http://www.rnajournal.org/cgi/doi/10.1261/rna.059808. 116. (bp) miRNA duplexes (Grishok et al. 2001; Hutvagner et al. 2001). One strand of the duplex is subsequently loaded onto the ARGONAUTE protein to form a functional miRNAinduced silencing complex (miRISC) (Hammond et al. 2001; Mourelatos et al. 2002).

DROSHA plays an irreplaceable role in miRNA biogenesis, as manifested by the complete abolishment of canonical miRNA expression in DROSHA knockout $(\mathrm{KO})$ cells (Kim et al. 2016). Human DROSHA contains proline-rich (Prich) and arginine/serine-rich (RS-rich) domains in the $\mathrm{N}$-terminal region, a central domain (CED) in the middle, and two RNase III domains (RIIIDa and RIIIDb) followed by a double-stranded RNA-binding domain (dsRBD) in the $\mathrm{C}$-terminal region. The $\mathrm{N}$-terminal domains are dispensable for pri-miRNA processing activity in vitro (Han et al. 2004; Nguyen et al. 2015), but appear to provide a regulatory platform for the protein by undergoing multiple post-translational modifications (Tang et al. 2010, 2011, 2013; Yang et al. 2015). For example, phosphorylation of Serine 300 and Serine302, located in the RS-rich domain, by glycogen synthase kinase $3 \beta$ (GSK3 $\beta$ ) facilitates nuclear localization of DROSHA (Tang et al. 2010, 2011). On the other hand, several

(C) 2017 Lee et al. This article is distributed exclusively by the RNA Society for the first 12 months after the full-issue publication date (see http://rnajournal. cshlp.org/site/misc/terms.xhtml). After 12 months, it is available under a Creative Commons License (Attribution-NonCommercial 4.0 International), as described at http://creativecommons.org/licenses/by-nc/4.0/. 
serine and threonine residues, including Serine300, are targeted by p38 mitogen-activated protein kinase (MAPK) under stress conditions, leading to nuclear export and subsequent degradation of DROSHA (Yang et al. 2015). The middle and C-terminal domains, in association with two DGCR8 molecules, constitute the catalytic core of the Microprocessor in which RIIIDa and RIIIDb dimerize intramolecularly to cleave the $3^{\prime}$ and $5^{\prime}$ strand of the miRNA hairpin, respectively (Han et al. 2004; Nguyen et al. 2015; Kwon et al. 2016). Recent biochemical and structural studies with purified Microprocessor revealed that DROSHA is the subunit that not only executes the catalysis but also determines the cleavage sites by measuring the distance from the basal junction between single-stranded RNA (ssRNA) and double-stranded RNA (dsRNA) (Nguyen et al. 2015; Kwon et al. 2016).

In addition to its role as the initiator of miRNA maturation, accumulating evidence suggests noncanonical functions of DROSHA (Burger and Gullerova 2015). The homeostatic maintenance of Microprocessor activity relies on the cleavage of pri-miRNA-like hairpin structures embedded in the DGCR8 mRNA by DROSHA (Han et al. 2009; Kadener et al. 2009; Triboulet et al. 2009). Besides this widespread and deeply conserved targeting, DROSHA directly controls the stability of several mRNAs in particular biological contexts (Kadener et al. 2009; Chong et al. 2010; Karginov et al. 2010; Knuckles et al. 2012; Macias et al. 2012; Johanson et al. 2015). For example, clearance of inhibitory mRNAs in progenitor cells by DROSHA-mediated cleavage has recently emerged as a means of regulating developmental pathways, as illustrated in neurogenesis (Knuckles et al. 2012; Marinaro et al. 2017) and myelopoiesis (Johanson et al. 2015). DROSHA also cleaves and destabilizes viral mRNA (Lin and Sullivan 2011) and retrotransposon transcripts (Heras et al. 2013), serving as a defender against the expression of deleterious elements. Notably, the products of these cleavage events seem unlikely to enter the miRNA pathway, as the corresponding small RNAs could only be detected, if at all, by deep sequencing. Cleavage-independent functions of DROSHA have also been reported, such as regulation of alternative splicing (Havens et al. 2014) and transcriptional activation (Gromak et al. 2013).

Precursor mRNA (pre-mRNA) splicing by the spliceosome and pri-miRNA cleavage by the Microprocessor are two major RNA processing events that occur cotranscriptionally in the nucleus (Pawlicki and Steitz 2010). Because miRNA sequences can be located anywhere in the genome, many primary transcripts serve simultaneously as premRNAs and pri-miRNAs. In this regard, understanding how the two distinct molecular machineries executing each of the processing reactions are coordinated for a single nascent transcript has been an active area of research. Processing of intronic miRNAs, which account for the majority of mammalian miRNAs, generally neither requires nor affects splicing of adjacent exons (Kim and Kim 2007; Kataoka et al. 2009), although a few reports demonstrated the existence of an interplay between the two processes in specific genomic contexts (Janas et al. 2011; Agranat-Tamir et al. 2014). Particularly interesting cases are miRNA hairpins overlapping with exonic sequences. A transcriptome-wide survey of DGCR8 binding sites revealed that DGCR8 makes contact with hundreds of cassette exons, possibly leading to modulation of alternative splicing (Macias et al. 2012). One of the target mRNA identified in this study, TCF7L1/ $T C F 3$, has recently been shown to play a role in stem cell differentiation through DGCR8-dependent alternative splicing control (Cirera-Salinas et al. 2017), underscoring the physiological relevance of the regulation. On the other hand, bioinformatics analysis revealed dozens of miRNAs whose hairpin precursors are located across exon-intron junctions (Mattioli et al. 2013; Melamed et al. 2013). In these situations, the splicing machinery and the Microprocessor compete with each other for a common substrate, although the molecular basis for such competition has remained elusive.

Here, we report that human DROSHA targets and regulates alternative splicing of its own nascent transcript. Mammalian DROSHA genes have evolved a conserved hairpin structure spanning the exon 7-intron 7 junction, which serves as a substrate for the Microprocessor complex in human cells but not in murine cells. We show that it is this hairpin element that determines whether DROSHA exon 7 is alternatively or constitutively spliced. We further demonstrate that the Microprocessor promotes skipping of exon 7 in human cells primarily through binding to the juxtaposed hairpin rather than cleaving it. Finally, we provide biochemical evidence that the suppressive effect of the Microprocessor on DROSHA exon 7 splicing involves sterically hindering the splicing machinery from recognizing its cognate splice site.

\section{RESULTS}

\section{The DROSHA hairpin}

While examining deep sequencing data of small RNAs expressed in HeLa cells (Shin et al. 2010), we observed two sets of reads mapped across the exon 7-intron 7 junction of the DROSHA pre-mRNA (Fig. 1A). These sets of reads were reminiscent of miRNA duplexes in that they were complementary to each other with $3^{\prime}$ overhangs and were predicted to constitute the apical stem of a hairpin structure (Fig. 1B). Searching for potential repetitive elements near the corresponding genomic region revealed the presence of a palindromic sequence likely derived from medium reiteration frequency 5A (MER5A) transposons (Fig. 1C). We annotated this 190-nt element as the human DROSHA hairpin. To investigate whether the DROSHA hairpin is evolutionarily conserved, we inspected the orthologous genomic regions of other vertebrate DROSHA genes. We found similar palindromic sequences in the genomes of most placental mammals, but not in those of chicken, frog, and zebrafish (Fig. 1B,C; Supplemental Fig. 1). 
A

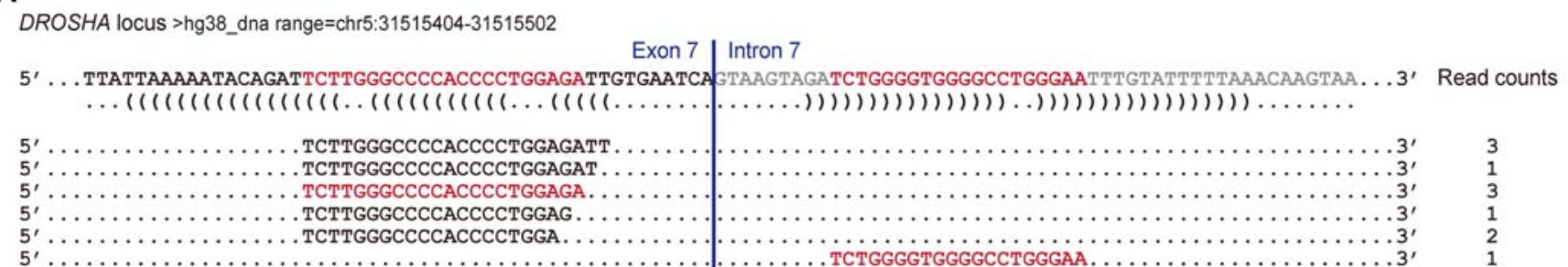

B

Human DROSHA hairpin

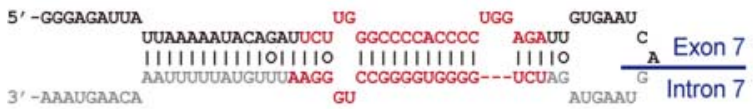

Mouse DROSHA hairpin

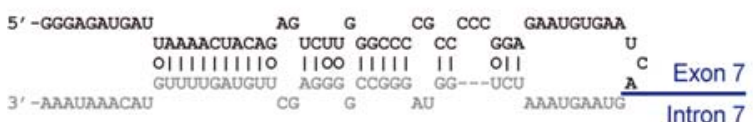

C

DROSHA locus >hg38 dna range=chr5:31514588-31515964

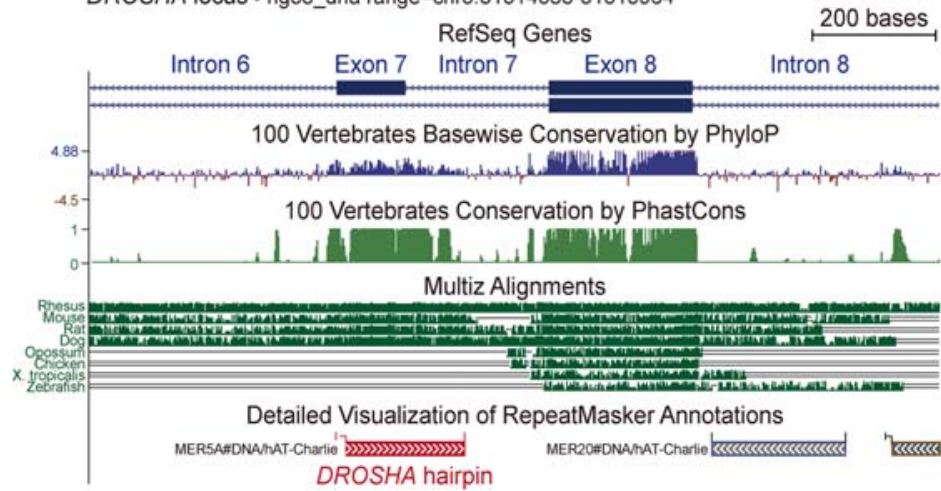

FIGURE 1. Structure and conservation of the DROSHA hairpin. (A) HeLa small RNA reads mapped across the exon 7 -intron 7 junction of the DROSHA pre-mRNA (Shin et al. 2010). The dominantly abundant small RNA species of each set is marked in red. Exonic and intronic sequences are presented in black and gray, respectively. (B) Predicted secondary structures of the human and mouse DROSHA hairpins, colored as in A. Prediction was performed using the mfold RNA-folding algorithm (Zuker 2003). (C) Evolutionary conservation of the DROSHA hairpin as shown in the UCSC Genome Browser (https://genome.ucsc.edu/). The DROSHA hairpin is indicated by a red bar.

\section{The human DROSHA hairpin is cleaved by the Microprocessor in vitro and in vivo}

Semblance of the DROSHA hairpin to pri-miRNAs raised the possibility that DROSHA may target its own transcript. First, we addressed whether the DROSHA hairpin could be cleaved by the Microprocessor complex in vitro. When human DROSHA hairpin RNA was incubated with Microprocessor lysate, prepared from HEK293T cells overexpressing both DROSHA and DGCR8, an 60-nt fragment was generated, demonstrating that this hairpin served as a genuine substrate for the Microprocessor in vitro (Fig. 2A). To rule out the possibility that the observed cleavage was due to an endoribonuclease other than DROSHA, we performed in vitro processing with a lysate containing an overexpressed DROSHA mutant, E110bQ. This DROSHA mutant, which carries a point mutation in RIIIDb and is, therefore, only capable of cleaving the $3^{\prime}$ strand of a hairpin, released a larger ( 140 nt) fragment, as expected (Fig. 2A). We cloned and sequenced the $\sim 60$-nt fragment generated from the human DROSHA hairpin to clarify its identity. The majority of clones (26 of 31) revealed cleavage sites consistent with Microprocessor-mediated processing, which leaves two staggered cuts approximately one helical turn ( $\sim 11$ bp) away from the basal ssRNA-dsRNA junction (Fig. 2B; Zeng et al. 2005; Han et al. 2006; Auyeung et al. 2013).
In stark contrast, the mouse DROSHA hairpin failed to be processed by any of the lysates despite its overall sequence and structural similarities to the human hairpin (Fig. 2A). We excluded the possibility of murine-specific factor(s) required for efficient processing of the mouse hairpin, because in vitro processing with a lysate or the endogenous Microprocessor immunopurified from mouse embryonic fibroblasts gave similar results (data not shown). This failure may be because of suboptimal stem length of or multiple mismatches in the mouse hairpin (Fig. 1B; Fang and Bartel 2015). To examine whether the processing defect is coupled to the lack of Microprocessor binding, we carried out in vitro RNA pulldown assay. Hairpin RNAs immobilized on agarose beads were incubated with HEK293T lysates containing the components of a catalytically deficient Microprocessor (trans-dominant negative [TN] DROSHA and/or DGCR8), and proteins specifically bound to the RNA were analyzed by Western blotting. Consistent with the results from in vitro processing, only the human DROSHA hairpin efficiently precipitated the Microprocessor or its dsRNA-binding subunit DGCR8 (Fig. 2C). Of note, TN DROSHA interacted with the human DROSHA hairpin only in the presence of DGCR8, emphasizing the role of DGCR8 as an obligate partner for DROSHA (Gregory et al. 2004; Han et al. 2004, 2006; Nguyen et al. 2015). 
A

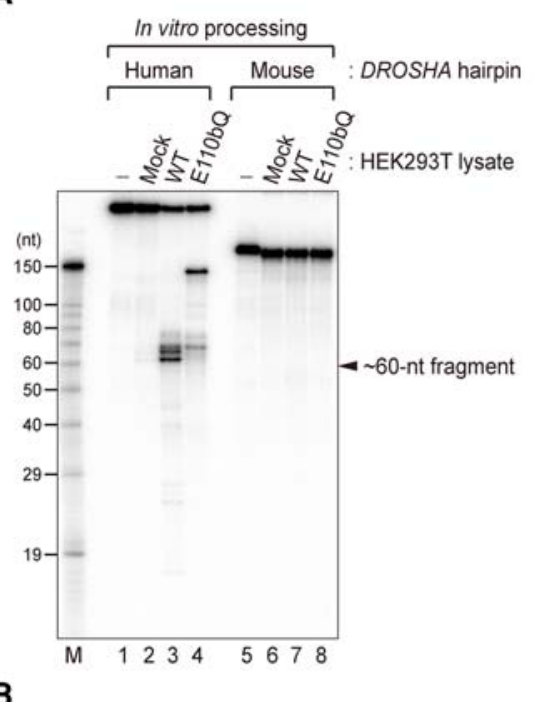

B

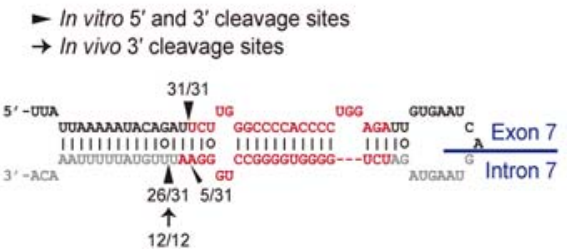

C

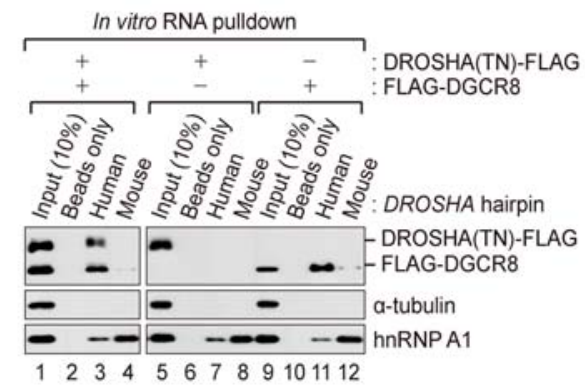

D

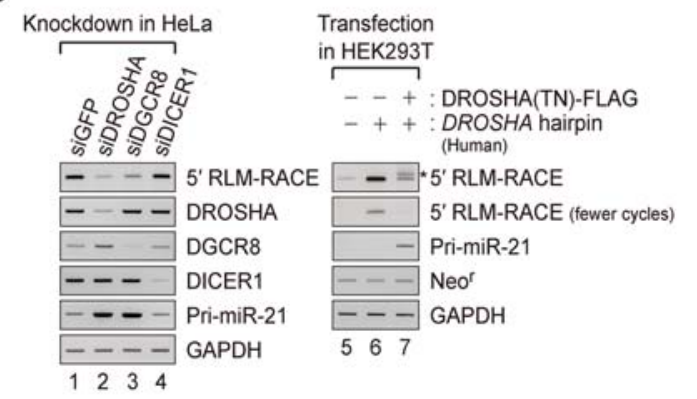

E



FIGURE 2. The human DROSHA hairpin is cleaved by the Microprocessor complex in vitro and in vivo. (A) In vitro processing of the DROSHA hairpin with Microprocessor lysates. Radiolabeled hairpin RNAs were incubated with lysates from HEK293T cells overexpressing either a wildtype (WT) or mutant (E110bQ) version of the Microprocessor. The pre-miRNA-like processing product of $\sim 60$-nt is indicated by an arrowhead. $(B)$ Determination of cleavage sites in the human DROSHA hairpin. The $\sim 60$-nt fragment from in vitro processing was gel-purified, cloned, and sequenced to determine the $5^{\prime}$ and $3^{\prime}$ cleavage sites (arrowhead). The in vivo $3^{\prime}$ cleavage site, as identified by cloning of the $5^{\prime}$ RLM-RACE product from HeLa cells, is also indicated (arrow). (C) In vitro RNA pulldown with the DROSHA hairpin. Cold hairpin RNAs covalently attached to agarose beads were incubated with lysates from HEK293T cells overexpressing the components of the Microprocessor, and bound proteins were analyzed by Western blotting. Tubulin serves as a negative control for pulldown. hnRNP A1 was used as a positive control, which turned out by mass spectrometric analyses to interact with both hairpin RNAs (data not shown). (D) $5^{\prime}$ RLM-RACE experiments to capture the $3^{\prime}$ processing product. Total RNAs from HeLa cells depleted of DROSHA, DGCR8, or DICER1 were subjected to $5^{\prime}$ RLM-RACE (left panel). PCR amplification was terminated in the linear phase ( 45 cycles) and nested PCR was omitted to prevent signal saturation. The accumulation of DGCR8 mRNA in DROSHA-depleted cells and of primiR-21 in DROSHA- or DGCR8-depleted cells confirms the functional knockdown of each protein. 5' RLM-RACE results for HEK293T cells overexpressing either the human DROSHA hairpin alone or both the hairpin and TN DROSHA are also shown (right panel). Derepression of pri-miR-21 serves as a positive control for TN DROSHA expression. Expression of the neomycin resistance gene $\left(\mathrm{Neo}^{\mathrm{r}}\right)$, which is encoded in the hairpin expression construct, reflects the transfection efficiency. The upper band marked with an asterisk is a heteroduplex species associated with overamplification. (E) Small RNA Northern blot analysis to detect processing products from the human DROSHA hairpin. The $\sim 60$-nt processing product is indicated by an arrowhead. Ethidium bromide staining of 5S rRNA serves as a loading control.

Next, we asked whether Microprocessor-mediated cleavage of the human DROSHA hairpin actually occurs in cells. We utilized RNA ligase-mediated rapid amplification of cDNA $5^{\prime}$ ends (5' RLM-RACE) to capture the $3^{\prime}$ processing product of the hairpin (Karginov et al. 2010; Shin et al. 2010). A reverse primer was designed to hybridize to human intron 7, and 5' RLM-RACE was performed on total RNA isolated from HeLa cells. RACE amplified a product of the expected size (Fig. 2D), which mapped the same $3^{\prime}$ cleavage site as determined by in vitro experiments (Fig. 2B). Notably, the intensity of the RACE product was markedly reduced when either DROSHA or DGCR8 was depleted by RNAi, suggesting a specific role of the Microprocessor in this cleavage event (Fig. 2D). Knockdown of DICER, another RNase III implicated in miRNA biogenesis, had no effect on the RACE signal. To further confirm that the RACE product indeed originated from the human DROSHA hairpin in a DROSHA-dependent manner, we transfected HEK293T cells with a plasmid in which the hairpin and its surrounding genomic sequences were placed under the control of the CMV promoter. Ectopic expression of the human DROSHA hairpin RNA gave rise to an intensified RACE product of exactly the same size, which was substantially diminished upon coexpression of TN DROSHA (Fig. 2D). We also performed Northern blot analysis to detect the $\sim 60$-nt processing product or the $\sim 22$-nt small RNA derived from it. We failed to observe any species on the blot when we used total RNA from mock-transfected HEK293T cells, indicating that the steady-state level of the processing product is generally low in normal conditions. However, overexpression of the 
A

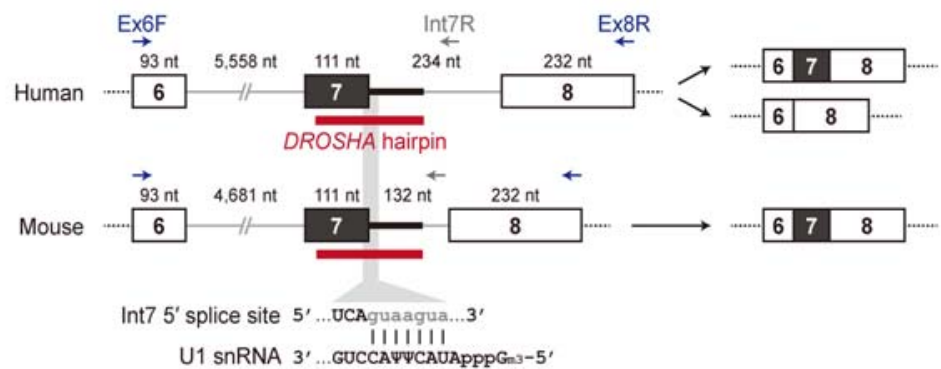

B

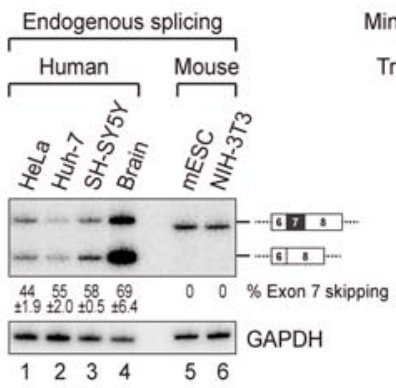

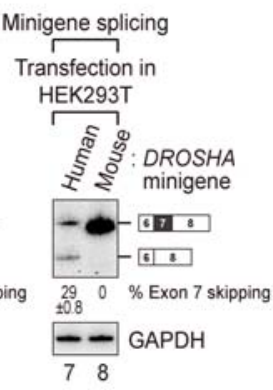

C

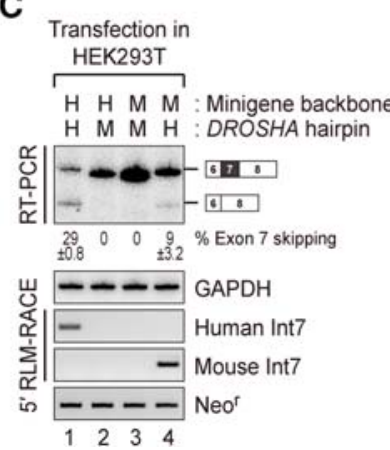

D



FIGURE 3. The human DROSHA hairpin is responsible for alternative splicing of DROSHA exon 7. (A) Schematic representation of the DROSHA gene region from exons 6-8. Boxes, horizontal lines, and the red bar across the exon 7-intron 7 junction depict exons, introns, and the DROSHA hairpin, respectively. PCR primers to detect exon 7 splicing or the $3^{\prime}$ processing product are represented by blue and gray arrows, respectively. It is noted that a vector-specific forward primer was used instead of Ex6F for the analysis of minigene splicing. The $5^{\prime}$ splice site of intron 7 and its base-pairing to U1 snRNA are also shown. (B) Splicing of DROSHA exon 7 in human and murine cells and its recapitulation in minigene systems. Percentages of the exon 7-skipped isoform and standard error of the mean (SEM) from three independent experiments are presented below the gel. (C) Hairpin swapping assay. The DROSHA hairpins were interchanged between the human and mouse minigenes and exon 7 splicing from these hybrid constructs was analyzed. $\mathrm{H}$ and $\mathrm{M}$ stand for human and mouse, respectively. $5^{\prime} \mathrm{RLM}$-RACE was also performed to indicate hairpin cleavage in cells. Percentages of the exon 7-skipped isoform and SEM from three biologically independent experiments are presented below the gel. GAPDH and $\mathrm{Neo}^{\mathrm{r}}$ serve as loading controls. (D) Psoralen crosslinking assay. Radiolabeled hairpin RNAs were incubated with HeLa nuclear extract (NE) under splicing conditions and irradiated with 365-nm UV light in the presence of psoralen. The U1 snRNA:DROSHA hairpin adducts are indicated by arrowheads. The shortened adducts resulting from RNase $\mathrm{H}$ digestion with an oligonucleotide complementary to U1 snRNA are marked by an arrow. Relative intensities of the adducts from five independent experiments are plotted on the graph. $\left.{ }^{* *}\right)$ Statistical significance of $P \leq 0.005$ as determined by Student's $t$-test. Error bars represent SEM.

hairpin led to an accumulation of the 60-nt fragment, which was no longer visible after TN DROSHA coexpression (Fig. 2E). Taken together, these results indicate that the human DROSHA hairpin is cleaved by the Microprocessor in vivo as well as in vitro.

It is of note that, even when we overexpressed the human DROSHA hairpin, we could barely detect the $\sim 22$-nt small RNA (Fig. 2E). This is consistent with the low number of sequencing reads mapped across the hairpin (Fig. 1A). Several reports have demonstrated that Microprocessormediated cleavage can be decoupled from miRNA biogenesis (Han et al. 2009; Triboulet et al. 2009; Knuckles et al. 2012; Johanson et al. 2015). One prominent example is a hairpin structure embedded in the $5^{\prime}$-untranslated region (5'-UTR) of the DGCR 8 mRNA, which is cleaved by the Microprocessor to generate an $~ 60$-nt RNA fragment that is largely confined to the nucleus (Han et al. 2009). However, the $\sim 60$-nt processing product from the ectopically expressed human DROSHA hairpin was exported to the cytoplasm as efficiently as a canonical pre-miRNA, pre-miR-143, suggesting that further processing defects exist downstream from nuclear export (Supplemental Fig. 2A). For example, a trinucleotide bulge positioned in the apical stem of the hairpin may impair DICER processing, because filling this bulge dramatically enhanced small RNA production (Supplemental Fig. 2B).

\section{The human DROSHA hairpin is responsible for the skipping of DROSHA exon 7}

Interestingly, exon 7 of the human DROSHA mRNA, which comprises the $5^{\prime}$ half of the human DROSHA hairpin, is annotated as an alternative exon (Fig. 3A). At the time of writing, RefSeq catalogs 11 splice isoforms for the human DROSHA gene, four of which lack exon 7 (NM_001100412.1, XM_017009401.1, XM_005248294.3, and XM_017009400.1) because of alternative splicing. In contrast, skipping of DROSHA exon 7 is not conserved in mouse; in RefSeq, all four mouse DROSHA transcripts contain exon 7. To validate this species-specific alternative 
splicing, we performed radioactive RT-PCR analysis using a panel of total RNAs of human (HeLa, Huh-7, SH-SY5Y, and whole brain) or mouse (mESC and NIH-3T3) origin. Amplification of the region between exons 6 and 8 from human cDNAs resulted in two distinct bands, which proved by cloning and sequencing to be splice isoforms differing in the presence or absence of exon 7 (Fig. 3B). It is noted that the relative abundance of the two isoforms varies substantially among different tissues, with the exon 7-skipped isoform being predominantly expressed in the brain (Supplemental Fig. 3). On the other hand, mouse cDNAs produced only one band corresponding to the full-length transcript, confirming constitutive splicing of DROSHA exon 7 in murine cells (Fig. 3B).

Given the importance of RNA secondary structure in the regulation of splicing (Jin et al. 2011; McManus and Graveley 2011), we speculated that the DROSHA hairpin may play a key role in determining whether, and if so, to what extent, exon 7 is skipped. To explore this possibility, we constructed splicing reporter minigenes by subcloning the genomic fragment spanning DROSHA exons 6-8 downstream from the CMV promoter. When transfected into HEK293T cells, these minigenes faithfully recapitulated the splicing patterns of their endogenous counterparts; the human DROSHA minigene produced both the full-length and exon 7-skipped isoforms, whereas the mouse minigene exclusively generated the full-length transcript (Fig. 3B). Next, we reciprocally swapped the DROSHA hairpin elements between the human and mouse minigenes and introduced these hybrid constructs into HEK293T cells. $5^{\prime}$ RLM-RACE experiments with reverse primers complementary to the diverged region of intron 7 demonstrated that only the human DROSHA hairpin was cleaved regardless of the surrounding genomic sequences (Fig. 3C). Notably, the human DROSHA minigene containing the mouse DROSHA hairpin no longer displayed exon 7 skipping. In contrast, the mouse minigene bearing the human DROSHA hairpin started to alternatively splice exon 7 (Fig. 3C). Similar results were obtained when we used HeLa cells or NIH-3T3 cells as transfection hosts, indicating that the fate of exon 7 as an alternative or a constitutive exon is dictated by primary sequence determinants in the minigenes rather than by cell type-specific or species-specific splicing factors (Supplemental Fig. 4). Of note, we reproducibly observed that skipping of exon 7 from the hybrid minigene was relatively inefficient compared to that from the wild-type human minigene (Fig. 3C; Supplemental Fig. 4). This indicated that additional cis-acting elements outside of the DROSHA hairpin may be in operation to modulate exon 7 splicing, for example, splicing enhancers in the murine genomic context. Nevertheless, these data strongly demonstrated that it is the DROSHA hairpin that makes the decision of whether to splice exon 7 alternatively or constitutively.

The human and mouse DROSHA hairpins exhibit $~ 84 \%$ nucleotide sequence identity, with the same 9-mer core sequence representing the $5^{\prime}$ splice site of intron $7\left(5^{\prime}\right.$ UCAguaagu- $3^{\prime}$, where the $3^{\prime}$ sequence of exon 7 is presented in uppercase) (Fig. 3A). We speculated that the same $5^{\prime}$ splice site may have differential affinity to U1 small nuclear ribonucleoprotein (U1 snRNP) in the context of the two different hairpins, possibly contributing to the different fates of exon 7. To test this, we measured U1 snRNP binding to the DROSHA hairpins in HeLa nuclear extract by psoralen crosslinking assay, which allows the detection of RNA-RNA interactions (Nilsen 2014). When DROSHA hairpin RNAs were incubated with HeLa nuclear extract and irradiated with long-wavelength UV light in the presence of psoralen, additional species migrating more slowly than the substrate were observed for both the human and mouse hairpins (Fig. 3D). RNase $\mathrm{H}$ digestion of the purified crosslinking reactions with a DNA oligonucleotide targeting the second loop of U1 snRNA (nt 64-75) increased the mobility of those species (Fig. 3D), indicating that they represent the DROSHA hairpins crosslinked to U1 snRNA. Notably, the human DROSHA hairpin reproducibly generated less intense signals for U1 snRNA-crosslinked species than the mouse hairpin (Fig. 3D), which supports our conclusion that the human, but not mouse, hairpin directs exon 7 skipping despite the identical $5^{\prime}$ splice site sequence shared by the two hairpins (Fig. 3C). It is possible that evolutionary nucleotide substitutions in the DROSHA hairpin may have disrupted or created cis-acting regulatory elements, thereby changing the repertoire of bound splicing factors and enabling differential recognition of the same $5^{\prime}$ splice site by U1 snRNP. Another nonmutually exclusive possibility is that alterations in the secondary structure of the DROSHA hairpin RNA may be responsible for the differential exon 7 selection. Supporting this idea, RNA secondary structure prediction revealed that the human DROSHA hairpin forms much more stable structures compared to those of the mouse hairpin $(\Delta G=$ approximately -93 to $-90 \mathrm{kcal} / \mathrm{mol}$ for the human DROSHA hairpin; $\Delta G=$ approximately -67 to $-63 \mathrm{kcal} / \mathrm{mol}$ for the mouse DROSHA hairpin) (Supplemental Fig. 1). Extensive intramolecular pairing in the human DROSHA hairpin may sequester splicing regulatory signals to some extent to drive exon 7 skipping.

\section{The Microprocessor modulates alternative splicing of human DROSHA exon 7 independently of DROSHA hairpin cleavage}

The observations that the human DROSHA hairpin is cleaved by the Microprocessor and that this element is necessary and sufficient to direct DROSHA exon 7 skipping prompted us to propose that the Microprocessor may modulate alternative splicing of human DROSHA exon 7. Two recent studies demonstrated the existence of miRNAs whose hairpin precursors overlap with exon-intron junctions (Mattioli et al. 2013; Melamed et al. 2013). In these situations, the splicing machinery and the Microprocessor competed with each other 
A
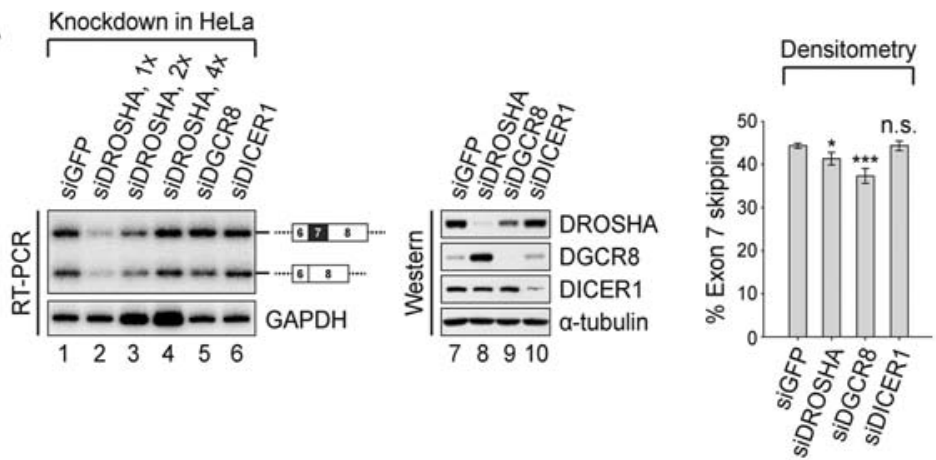

B

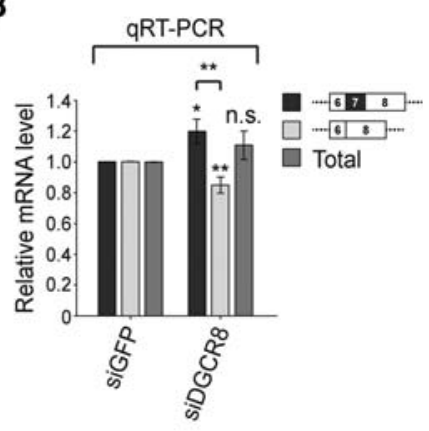

C
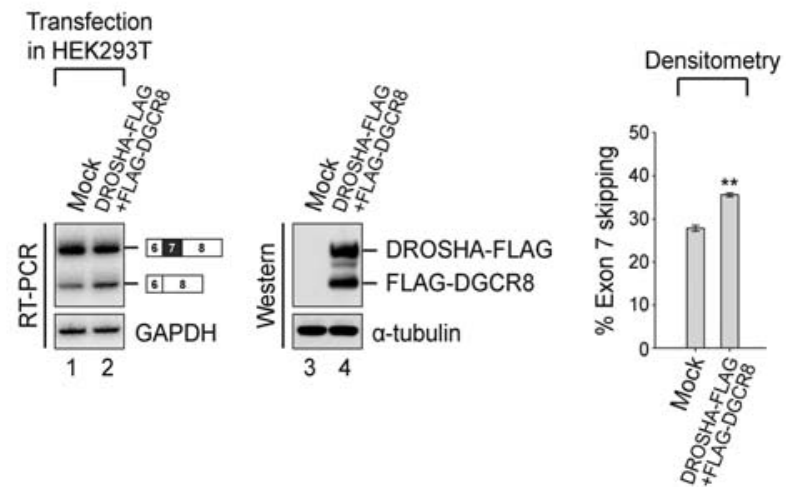

FIGURE 4. The Microprocessor regulates alternative splicing of human DROSHA exon 7. (A) Endogenous splicing of DROSHA exon 7 in HeLa cells depleted of DROSHA, DGCR8, or DICER. For DROSHA knockdown, increasing amounts of cDNA were used in amplification to obtain band intensities that were similar to those of the other samples. Percentages of the exon 7-skipped isoform from five biologically independent experiments are plotted on the graph. (B) qRT-PCR measurement of splice isoforms in DGCR8-depleted HeLa cells. Primers spanning specific exon-exon junctions were used to quantify each splice isoform individually. The total DROSHA mRNA level was measured by amplifying the region between exons 29 and 30. Relative transcript levels from five biologically independent experiments are plotted on the graph. (C) Splicing of the human DROSHA minigene in HEK293T cells following overexpression of the Microprocessor. Percentages of the exon 7-skipped isoform from three biologically independent experiments are plotted on the graph. $\left({ }^{*}\right) P \leq 0.05,\left(^{* *}\right) P \leq 0.005$, and $\left({ }^{* * *}\right) P \leq 0.0005$ indicate statistical significance as determined by Student's $t$-test. n.s., not significant. Error bars represent SEM.

for a single nascent transcript, such that knockdown of DROSHA or DGCR8 led to increased exon inclusion. To test whether similar regulation is operational on the human DROSHA hairpin, we depleted the components of the Microprocessor in HeLa cells by RNAi and investigated endogenous splicing patterns of DROSHA exon 7. Reduction of Microprocessor activity indeed resulted in increased inclusion of DROSHA exon 7, suggesting that the Microprocessor interfered with splicing of this alternative exon (Fig. 4A). The change in alternative splicing was not due to a loss of small RNAs, as depletion of DICER did not alter the ratio of the two splice isoforms. Interestingly, we reproducibly observed a stronger effect on exon 7 splicing by knocking down DGCR8, compared with DROSHA, which may be explained by the well-established cross-regulation between DROSHA and DGCR8 (Han et al. 2009; Kadener et al. 2009; Triboulet et al. 2009). As DGCR8 stabilizes the DROSHA protein through protein-protein interactions (Han et al. 2009; Nguyen et al. 2015; Kwon et al. 2016), knockdown of DGCR8 decreases the protein levels of both DROSHA and DGCR8 (Fig. 4A). On the other hand, depletion of
DROSHA causes significant up-regulation of the level of DGCR8 protein (Fig. 4A), which alone is capable of binding to the human DROSHA hairpin (Fig. 2C). The increased free DGCR8 molecules in DROSHA-depleted cells may adversely affect exon 7 inclusion and partially compensate for the reduction of Microprocessor activity.

It has been suggested that the $5^{\prime}$ and $3^{\prime}$ flanking fragments generated by Microprocessor-mediated processing are rapidly degraded by exonucleases such as XRN2 and nuclear exosome (Morlando et al. 2008; Ballarino et al. 2009). In this regard, it is possible that Microprocessor activity promotes degradation of exon 7-containing nascent transcripts and thereby simply overrepresents the level of the exon 7-skipped isoform in conventional RT-PCR, rather than actually regulating exon 7 splicing. To test this possibility, we measured the relative abundance of each splice isoform in mock- or DGCR8-depleted HeLa cells by quantitative RT-PCR (qRTPCR) experiments. Notably, knockdown of DGCR8 not only up-regulated the level of the exon 7-containing isoform, but it also down-regulated the level of the exon 7-skipped isoform without altering the level of total DROSHA mRNAs 
A

A Transfection in DROSHA KO HCT116
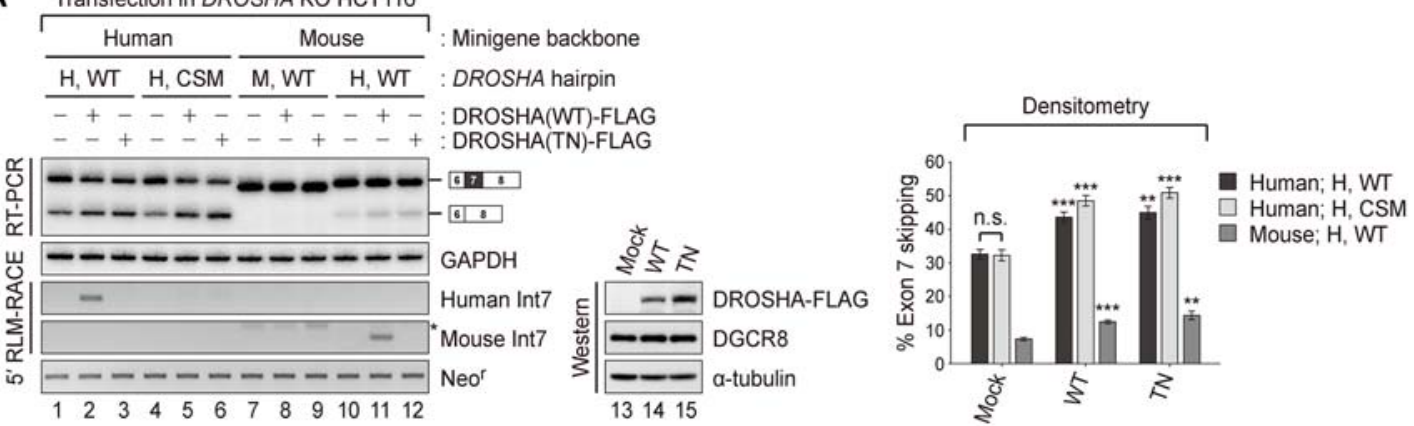

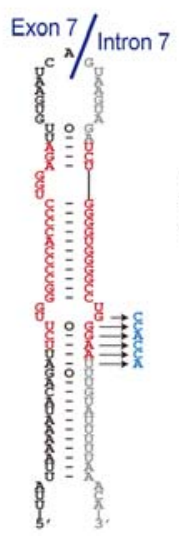

C



Transfection in DROSHA KO HCT116 followed by RNA immunoprecipitation

\begin{tabular}{|c|c|c|c|c|}
\hline \multicolumn{2}{|c|}{ Input (10\%) } & \multicolumn{2}{|c|}{ FLAG-IP } & \\
\hline Human & Mouse & Human & Mouse & Minigene backbone \\
\hline $\begin{array}{cc}\mathrm{H}, & \mathrm{H}, \\
\mathrm{WT} & \mathrm{CSM}\end{array}$ & $\begin{array}{cc}M, & H, \\
W T & W T\end{array}$ & $\begin{array}{cc}\mathrm{H}, \quad \mathrm{H}, \\
\mathrm{WT} & \mathrm{CSM}\end{array}$ & $\begin{array}{cc}\text { M, } & \mathrm{H}_{1} \\
\mathrm{WT} & \mathrm{WT}\end{array}$ & DROSHA hairpin \\
\hline$\overline{-+} \overline{-+}$ & $\overline{-+} \overline{-+}$ & $\overline{-+} \overline{-+}$ & $\overline{-+} \overline{-+}$ & DROSHA(TN)-FLAG \\
\hline -ー- & ---- & - & - & $--\square$ (Unspliced) \\
\hline ニニニニ & $=----$ & & & $\models \frac{67}{0}:$ (Spliced) \\
\hline -ーー - & - - - & $-\quad-$ & $-\quad-$ & Pri-miR-21 \\
\hline--- & ---- & & & GAPDH \\
\hline
\end{tabular}

D

Psoralen crosslinking

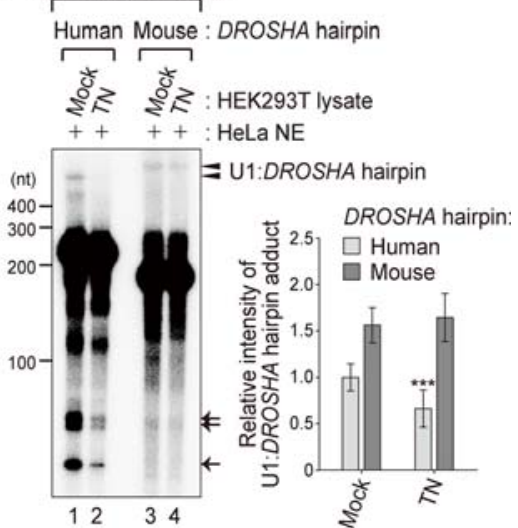

FIGURE 5. The Microprocessor-mediated suppression of DROSHA exon 7 splicing occurs independently of DROSHA hairpin cleavage. (A) Minigene splicing in DROSHA KO HCT116 cells replenished with wild-type (WT) or catalytically inactive (TN) DROSHA. H and M stand for human and mouse, respectively. $5^{\prime}$ RLM-RACE was performed to indicate hairpin cleavage in cells. The upper band marked with an asterisk indicates a nonspecific amplification product independent of hairpin cleavage. GAPDH and $\mathrm{Neo}^{\mathrm{r}}$ serve as loading controls. Percentages of the exon 7-skipped isoform from three biologically independent experiments are plotted on the graph. $\left.{ }^{* *}\right) P \leq 0.005$ and $\left.{ }^{* * *}\right) P \leq 0.0005$ indicate statistical significance as determined by Student's $t$-test. n.s., not significant. Error bars represent SEM. (B) Cleavage site mutant (CSM) of the human DROSHA hairpin. The $3^{\prime}$ cleavage site was mutated at the indicated positions to disrupt base-pairing, which effectively prevented Microprocessor-mediated cleavage, as confirmed by the in vitro DROSHA processing assay. (C) RNA immunoprecipitation assay. Transfected DROSHA KO HCT116 cells were crosslinked with formaldehyde, lysed, and subjected to immunoprecipitation using an anti-Flag antibody. Coprecipitated RNA was analyzed by RT-PCR. H and $\mathrm{M}$ stand for human and mouse, respectively. An intron 7-specific forward primer and a vector-specific reverse primer were used to detect nascent transcripts. Pri-miR-21 and GAPDH serve as positive and negative controls for DROSHA-Flag immunoprecipitates, respectively. (D) Psoralen crosslinking assay in the presence of Microprocessor lysate. Binding reactions for crosslinking were supplemented with mock or Microprocessor lysate containing TN DROSHA. The U1 snRNA:DROSHA hairpin adducts are indicated by arrowheads. The fragments generated by Microprocessor-mediated cleavage of the human DROSHA hairpin are indicated by arrows. Relative intensities of the adducts from five independent experiments are plotted on the graph. $\left(^{* * *}\right)$ Statistical significance of $P \leq 0.0005$ as determined by Student's $t$-test. Error bars represent SEM.

(Fig. 4B), which is expected if the observed effect of the Microprocessor on DROSHA exon 7 splicing represents true regulation rather than simple degradation.

To confirm the result from the knockdown experiments, we transiently transfected HEK293T cells with the human DROSHA minigene and examined splicing patterns in the presence of additional DROSHA and DGCR8 proteins. Overexpression of the Microprocessor caused a shift in minigene splicing toward exon 7 skipping, confirming the inhibitory role of this complex in the splicing of DROSHA exon 7 (Fig. 4C).

In principle, the Microprocessor-mediated cleavage of miRNA hairpins that are juxtaposed with splice sites would make the overlapping exons permanently unavailable for splicing. To investigate whether cleavage of the DROSHA hairpin is required for exon 7 skipping, we introduced the human DROSHA minigene into DROSHA KO HCT116 cells in which Microprocessor activity is completely extinguished (Kim et al. 2016). Exon 7 was still spliced alternatively in DROSHA KO cells, indicating that hairpin cleavage per se is not a prerequisite for exon 7 skipping (Fig. 5A). Furthermore, replenishment of KO cells with TN DROSHA, which is catalytically inert, as well as wild-type DROSHA, tilted minigene splicing in favor of exon 7 skipping to similar extents, demonstrating that the catalytic activity of DROSHA is dispensable for promoting exon 7 skipping (Fig. 5A). We also generated a minigene in which the cleavage site of the human DROSHA hairpin was mutated to prevent Microprocessor-mediated processing (Fig. 5B). Notably, the minigene bearing the cleavage site mutant (CSM) DROSHA 
hairpin produced the two splice isoforms and responded to coexpression of wild-type or TN DROSHA in DROSHA $\mathrm{KO}$ cells very similarly to the wild-type minigene (Fig. 5A). The nascent transcripts from both minigenes were precipitated by TN DROSHA as efficiently and specifically as an endogenous target, pri-miR-21, suggesting that the observed effect of DROSHA on splicing regulation likely emanated from its physical interactions with RNA (Fig. 5C).

To be certain that the human DROSHA hairpin is responsible for the splicing inhibition and binding of the minigene transcript by DROSHA, we examined the behaviors of the mouse DROSHA minigene and its hybrid mutant containing the human DROSHA hairpin in DROSHA KO cells. While the mouse minigene was neither differentially spliced upon DROSHA overexpression nor bound by DROSHA as anticipated, transplantation of the human DROSHA hairpin allowed the hybrid minigene to respond to and interact with DROSHA in the same way that the human minigenes did (Fig. 5A,C). Taken together, these data indicate that the Microprocessor impedes splicing of DROSHA exon 7 in human cells primarily through binding to the DROSHA hairpin rather than cleaving it.

Given that the catalytic activity of DROSHA is dispensable for regulating exon 7 splicing, we speculated that the Microprocessor may promote exon 7 skipping by occupying the human DROSHA hairpin and sterically hindering U1 snRNP from recognizing the $5^{\prime}$ splice sites. To investigate this possibility, we supplemented binding reactions for psoralen crosslinking with either mock or Microprocessor lysate containing TN DROSHA. Addition of Microprocessor lysate significantly impaired cleavage of the human DROSHA hairpin by endogenous DROSHA (Fig. 5D), indicating the existence of robust interactions between exogenous TN DROSHA and the human hairpin. Notably, crosslinking to U1 snRNA was substantially diminished under these conditions only for the human DROSHA hairpin (Fig. 5D), which was expected from our hypothesis. This observation demonstrates that the restricted access of U1 snRNP to the $5^{\prime}$ splice site mediated by the Microprocessor contributes to the suppressive effect of this complex on human DROSHA exon 7 splicing.

\section{DISCUSSION}

In this study, we examined the role of a specific structural element, the DROSHA hairpin, in the regulation of alternative splicing. The DROSHA hairpin is comprised of a genomic region that spans the junction between exon 7 and intron 7 of the DROSHA pre-mRNA and is evolutionarily conserved among placental mammals (Fig. 1). In human cells, this hairpin is recognized and cleaved by the Microprocessor complex, the catalytic subunit of which is DROSHA (Fig. 2). Such targeting is not observed in murine cells despite overall sequence and structural homologies between the human and mouse hairpins (Figs. 1,2). We demonstrated that the human
DROSHA hairpin is necessary and sufficient to direct skipping of DROSHA exon 7, which occurs in human cells but not in murine cells (Fig. 3). Based on these findings, we showed that the Microprocessor promotes exon 7 skipping in human cells and that this effect mainly stems from Microprocessor binding to the DROSHA hairpin rather than hairpin cleavage (Figs. 4, 5).

The DROSHA hairpin is classified by RepeatMasker as a derivative of MER5A transposable elements, which emerged in placental mammals (Fig. 1C). The palindromic nature of many transposons makes them plausible candidates for the evolutionary origin of miRNA genes (Piriyapongsa et al. 2007; Roberts et al. 2014; Qin et al. 2015). For example, the placental-specific miR-1302 family was recently proposed to have originated from MER53 transposons (Yuan et al. 2010). It is noteworthy that one repeat element introduced in the last common ancestor has diverged in some species to serve as a hairpin precursor for miR-1302, while in other species it has remained biologically inert (Yuan et al. 2010). This is strongly reminiscent of the DROSHA hairpin, which is cleaved by the Microprocessor in human cells but not in murine cells (Fig. 2). Analogous to the miR-1302 hairpins, the DROSHA hairpin may have acquired regulatory potential in a species-specific manner.

Recently, two independent groups systematically identified dozens of annotated miRNAs whose hairpin precursors are located across exon-intron junctions (Mattioli et al. 2013; Melamed et al. 2013). By using minigene assays and extensive mutagenesis studies, they experimentally validated functional antagonism between the splicing machinery and the Microprocessor, which we also observed in the case of the human DROSHA hairpin (Figs. 4, 5). In line with these findings, we provided biochemical evidence that the suppressive effect of the Microprocessor on DROSHA exon 7 splicing does not depend on the catalytic activity of DROSHA and involves sterically hindering the splicing machinery from recognizing its cognate splice site (Fig. 5). Further studies are needed to reveal whether similar mechanisms operate in other cases of splice-site-overlapping miRNAs.

Interestingly, it appears that the Microprocessor does not always compete with the splicing machinery when they share a common substrate. For example, the alternatively spliced exon 5 of the eIF4H pre-mRNA folds into a pri-miRNAlike hairpin structure, which is cleaved by DROSHA in vitro and in cells (Havens et al. 2014). However, the primary role of DROSHA here is to promote inclusion of exon 5 through an as-yet-uncharacterized, cleavage-independent mechanism (Havens et al. 2014). Processing of the miR-211 hairpin present in intron 6 of the TRPM1 pre-mRNA stimulates splicing of adjacent exons (Janas et al. 2011). DGCR8 binds to a hairpin structure embedded in intron 4 of the TCF7L1/ TCF3 pre-mRNA and ensures the correct splicing, which is necessary for the differentiation of mouse embryonic stem cells (Cirera-Salinas et al. 2017). These findings are hard to digest with the currently known functions of the 
Microprocessor, but may be supported by physical association between the spliceosome and the Microprocessor components (Gregory et al. 2004; Kataoka et al. 2009; AgranatTamir et al. 2014). It will be interesting to investigate the detailed mechanisms by which the Microprocessor facilitates splicing and to draw underlying commonalities from these seemingly unrelated regulatory events.

In vertebrate DROSHA, exons 5 to 8 encode the $\mathrm{N}$-terminal RS-rich domain, the function of which is largely unexplored. What are the biological consequences of DROSHA exon 7 skipping? It is noted that the majority of exon 7 sequences overlap with the $5^{\prime}$ half of the DROSHA hairpin (Fig. 1C), suggesting a coevolution of exon 7 with the hairpin. Consistent with this idea, exon 7 is found only in placental mammals while the neighboring exons are traceable in nonmammalian vertebrates, including chicken, frog, and zebrafish, as well as in mammals (Supplemental Fig. 5). Possibly reflecting its relatively recent emergence, we noticed that the protein region encoded by exon 7 exhibits slightly different physicochemical properties. For example, exon 7 encodes several hydrophobic amino acid residues, which creates a local hydrophobic patch within the long hydrophilic stretch of the RS-rich domain (Supplemental Fig. 5). The RS-rich domains found in many splicing factors are primarily involved in protein-protein interactions (Long and Caceres 2009; Shepard and Hertel 2009); therefore, interruption of RS-rich domain hydrophilicity by the presence of exon 7 may change the repertoire of interaction partners for DROSHA, which has indeed been shown to associate with a variety of auxiliary cofactors in addition to DGCR8 (Gregory et al. 2004). Interestingly, two recent studies independently reported alternative splicing of human DROSHA exon 7 and found that DROSHA proteins generated from exon 7-skipped isoforms were exclusively nuclear while those from exon 7-containing isoforms were also present in the cytoplasm (Dai et al. 2016; Link et al. 2016). One possibility is that the hydrophobic nature of the exon 7-encoded region may impair nuclear localization or facilitate nuclear export of the protein.

We observed that the ratio of the two splice isoforms resulting from exon 7 alternative splicing varies among different human tissues and that, unlike in other tissues, the exon 7-skipped isoform is dominantly abundant in the brain (Fig. 3B; Supplemental Fig. 3). Indeed, a recent large-scale analysis of RNA-seq data sets from diverse cell and tissue types annotated human DROSHA exon 7 as an alternative exon that exhibits increased skipping in neural tissues (Irimia et al. 2014). Mounting evidence suggests that Microprocessor activity and specificity is dynamically regulated in a tissuespecific or developmental stage-specific manner. For example, Microprocessor-mediated processing of pri-miR-7-1 is inhibited in non-neural cells by Musashi homolog 2 (MSI2) and $\mathrm{Hu}$ antigen $\mathrm{R}$ (HuR), which together bind to and stabilize the hairpin (Choudhury et al. 2013). Phosphorylated methyl-CpG binding protein 2 (MeCP2) interferes with the assembly of the Microprocessor by sequestering DGCR8 and suppresses the expression of a subset of miRNAs, which is alleviated upon neuronal calcium signaling by rapid dephosphorylation of MeCP2 (Cheng et al. 2014). TAR DNA-binding protein (TDP-43) has been reported to control the stability and substrate specificity of the Microprocessor during neuronal differentiation (Kawahara and Mieda-Sato 2012; Di Carlo et al. 2013). Similarly, the recognition and processing of the DROSHA hairpin by the Microprocessor may be differentially regulated in a spatiotemporal manner, possibly contributing to the varying degree of exon 7 splicing in different tissues. Further investigation is required to uncover the full extent and the biological significance of this additional layer in the control of human DROSHA expression.

\section{MATERIALS AND METHODS}

\section{Plasmids}

To generate a human DROSHA exons 6-8 minigene, the genomic fragment encompassing the first nucleotide of exon 6 to the last nucleotide of exon 8 was amplified from human B lymphoblast genomic DNA (ATCC) and cloned into pGEM-T Easy (Promega). We reduced the size of intron 6 (5558 nt) to $973 \mathrm{nt}$ such that the reduced intron 6 contained nt 1-345 and 4931-5558 of the original sequence. The resulting fragment was subcloned into the HindIII/ NotI site of pcDNA3.1 (Thermo Fisher Scientific). A mouse minigene was constructed similarly, with intron 6 (4681 nt) reduced to $969 \mathrm{nt}$ at the orthologous position. A pri-miR-143 expression plasmid was generated by subcloning a genomic fragment corresponding to the miR-143 hairpin with flanking sequences into the HindIII/EcoRI site of pcDNA3.1. pCK-DROSHA-Flag and pCKFlag-DGCR8 were kindly provided by Dr. V. Narry Kim (Seoul National University). Site-directed mutagenesis was carried out by standard inverse PCR procedures. Primer sequences are listed in Supplemental Table 1.

\section{Cell culture and transfection}

HEK293T and HeLa cells were maintained in DMEM (WelGene) supplemented with 10\% FBS (WelGene). DROSHA KO HCT116 cells (a generous gift from Dr. V. Narry Kim) were cultured in McCoy's 5A media (WelGene) containing 10\% FBS. NIH-3T3 cells were grown in DMEM supplemented with $10 \%$ BCS (WelGene). All cell lines used in this study were regularly tested for mycoplasma contamination. For RNAi experiments, cells were transfected with $8 \mathrm{nM}$ siRNA using Lipofectamine 2000 (Thermo Fisher Scientific) and incubated for $72 \mathrm{~h}$. The sequences of siRNAs are provided in Supplemental Table 1. Plasmid transfection was performed using Lipofectamine 2000, with $1 \mu \mathrm{g}$ of minigene plasmid and $2 \mu \mathrm{g}$ of effector plasmid delivered per 35-mm dish. Cells were harvested $48 \mathrm{~h}$ after plasmid transfection.

\section{RNA measurement}

Total RNA was prepared using TRI Reagent (Thermo Fisher Scientific), according to the manufacturer's instructions. RNAs 
to be reverse transcribed were further treated with Recombinant DNase I (Takara) to remove contaminating genomic DNA. Human tissue RNAs were from the Human Total RNA Master Panel II (Clontech) and were directly used in reverse transcription. $5^{\prime}$ RLM-RACE was performed using the GeneRacer Kit (Thermo Fisher Scientific) with minor modifications. Briefly, $5 \mu \mathrm{g}$ of DNase-treated total RNA was ligated to $250 \mathrm{ng}$ of GeneRacer RNA Oligo using T4 RNA Ligase (Thermo Fisher Scientific). After phenol extraction and ethanol precipitation, the 5'-ligated RNA was reverse transcribed with random hexamer and PrimeScript Reverse Transcriptase (Takara). PCR amplification was terminated during the linear phase and the PCR products were resolved on a $2 \%$ agarose gel. For analysis of splice isoforms, we performed radioactive RT-PCR by including $5^{\prime}$ end-labeled forward primers in reactions at $\sim 20 \mathrm{nM}$. Densitometric analysis of splice isoforms was carried out using Multi Gauge V3.0 (Fujifilm) or ImageJ (National Institutes of Health) softwares. Quantitative RT-PCR measurement of splice isoforms based on the comparative Ct method with SYBR Green was conducted with LightCycler 480 Instrument II (Roche Life Science). Human GAPDH mRNA was amplified as an endogenous control. Primer sequences are listed in Supplemental Table 1. For small RNA Northern blot analysis, $20 \mu \mathrm{g}$ of total RNA was separated on a $12.5 \%$ urea-polyacrylamide gel and transferred to Hybond $\mathrm{N}+$ nylon membrane (GE Healthcare Life Sciences). An antisense oligonucleotide probe corresponding to the DROSHA small RNA 5p (5'-UCUUGGGCCCCACCCCUGGAGA-3') was prepared using the StarFire miRNA Detection Kit (Integrated DNA Technologies). Probes for miR-143, tRNA ${ }^{\text {Lys }}$, and U1 snRNA were generated by standard $5^{\prime}$ end-labeling reactions using T4 Polynucleotide Kinase (Takara).

\section{Western blot analysis}

Cells were harvested and lysed in RIPA buffer (50 mM Tris- $\mathrm{HCl}$ at $\mathrm{pH}$ 8.0, $150 \mathrm{mM} \mathrm{NaCl}, 1 \% \mathrm{NP}-40,0.5 \%$ sodium deoxycholate, $0.1 \%$ SDS, $1 \times$ cOmplete Protease Inhibitor Cocktail [Roche Life Science]) on ice for $30 \mathrm{~min}$. Thirty to fifty micrograms of lysate were separated on a $10 \%$ SDS-polyacrylamide gel and transferred to Immobilon-P PVDF membrane (EMD Millipore). The primary antibodies used in this study were rabbit anti-Flag (Sigma, F7425), rabbit anti- $\alpha-$ tubulin (Abcam, ab52866), mouse anti-hnRNP A1 (4B10; EMD Millipore, 05-1521), rabbit anti-DROSHA (Abcam, ab12286), rabbit anti-DGCR8 (a gift from Dr. V. Narry Kim), and rabbit anti-DICER1 (Abcam, ab13502).

\section{In vitro DROSHA processing and directional cloning of the processing product}

Microprocessor lysate was prepared as described elsewhere (Lee and Kim 2007; Auyeung et al. 2013) with minor modifications. Briefly, HEK293T cells cotransfected with pCK-DROSHA-Flag and pCKFlag-DGCR8 were dispersed in Buffer D (20 mM HEPES-KOH at pH 7.9, $100 \mathrm{mM} \mathrm{KCl,} 0.2 \mathrm{mM}$ EDTA, 5 mM DTT, 10\% glycerol, $1 \times$ cOmplete Protease Inhibitor Cocktail) and lysed by sonication. After centrifugation at $15,000 \mathrm{rpm}$ at $4^{\circ} \mathrm{C}$ for $15 \mathrm{~min}$, the supernatant was collected as Microprocessor lysate. In vitro DROSHA processing was performed in $10-\mu \mathrm{L}$ reactions containing $\sim 10 \mathrm{nM}$ $\left[a-{ }^{32} \mathrm{P}\right]$ UTP-labeled RNA substrate, $50 \%(\mathrm{v} / \mathrm{v})$ of Microprocessor lysate $(5 \mu \mathrm{g} / \mu \mathrm{L})$, and $6.4 \mathrm{mM} \mathrm{Mg}(\mathrm{OAc})_{2}$ with incubation at $37^{\circ} \mathrm{C}$ for $30 \mathrm{~min}$. Reactions were quenched by treating with Proteinase $\mathrm{K}$ (Roche Life Science) at $60^{\circ} \mathrm{C}$ for $20 \mathrm{~min}$ and then purified by phenol extraction and ethanol precipitation. The reaction products were separated on a $12.5 \%$ urea-polyacrylamide gel and analyzed by phosphorimaging (Fujifilm BAS-2500). For directional cloning of the $\sim 60$-nt processing product, the corresponding band was gel-purified, sequentially ligated to $3^{\prime}$ and $5^{\prime}$ adaptors, amplified by RTPCR, and subcloned into pGEM-T Easy.

\section{RNA pulldown assay}

RNA pulldown was performed as described elsewhere (Michlewski and Caceres 2010) with minor modifications. One hundred pmoles $(\sim 6 \mu \mathrm{g})$ of cold hairpin RNA were $3^{\prime}$ oxidized with sodium $m$-periodate (Sigma) and covalently attached to $25 \mu \mathrm{L}$ of adipic acid dihydrazide agarose beads (Sigma). The beads were extensively washed with $2 \mathrm{M} \mathrm{KCl}$, equilibrated with Buffer $\mathrm{D}$, and then incubated with $\sim 1 \mathrm{mg}$ of Microprocessor lysate in $100-\mu \mathrm{L}$ reactions in the presence of $1.6 \mathrm{mM} \mathrm{Mg}(\mathrm{OAc})_{2}$ at RT for $2 \mathrm{~h}$ with constant rotation. After washing with Buffer D containing $1.6 \mathrm{mM} \mathrm{Mg}(\mathrm{OAc})_{2}$ four times, proteins specifically bound to the RNA were eluted by treating the beads with RNase Cocktail (Thermo Fisher Scientific) at $37^{\circ} \mathrm{C}$ for $30 \mathrm{~min}$ and analyzed by Western blotting.

\section{Psoralen crosslinking assay}

HeLa nuclear extract was prepared as previously described (Dignam et al. 1983). For psoralen crosslinking, $\sim 10 \mathrm{nM}\left[\alpha^{32} \mathrm{P}\right] \mathrm{UTP}-$ labeled RNA substrate was incubated in $10-\mu \mathrm{L}$ reactions with $50 \%(\mathrm{v} / \mathrm{v})$ of HeLa nuclear extract, $0.5 \mathrm{mM}$ ATP, $20 \mathrm{mM}$ creatine phosphate, and $1.6 \mathrm{mM} \mathrm{Mg}(\mathrm{OAc})_{2}$ at $30^{\circ} \mathrm{C}$ for $15 \mathrm{~min}$, supplemented with $2.5 \mu \mathrm{L}$ of $4^{\prime}$-aminomethyltrioxsalen hydrochloride (200 ng/ $\mu \mathrm{L}$; Sigma) and immediately irradiated with $365-\mathrm{nm}$ UV light for $15 \mathrm{~min}$. Reactions were quenched by treating with Proteinase $\mathrm{K}$ (Roche Life Science) at $60^{\circ} \mathrm{C}$ for $20 \mathrm{~min}$ and then purified by phenol extraction and ethanol precipitation. To identify the U1 snRNA:substrate crosslinked species, purified crosslinking products were annealed to a DNA oligonucleotide complementary to U1 snRNA nt 64-75 and treated with RNase $\mathrm{H}$ (Thermo Fisher Scientific) at $37^{\circ} \mathrm{C}$ for $30 \mathrm{~min}$. The crosslinking products were separated on a $6 \%$ urea-polyacrylamide gel and analyzed by phosphorimaging (Fujifilm BAS-2500). For the competition assay presented in Figure 5D, 30\% (v/v) of mock or Microprocessor lysate $(25 \mu \mathrm{g} / \mu \mathrm{L})$ prepared from transfected HEK293T cells was supplemented in the crosslinking reactions. The relative intensity of the U1 snRNA:DROSHA hairpin adduct was calculated by normalizing the intensity of the adduct by the intensity over the whole lane.

\section{RNA immunoprecipitation}

RNA immunoprecipitation was performed as described elsewhere (Niranjanakumari et al. 2002) with minor modifications. Fortyeight hours after transfection, cells were fixed in $0.5 \%$ formaldehyde in $1 \times$ PBS at RT for $5 \mathrm{~min}$ and lysed in RIPA buffer on ice for $30 \mathrm{~min}$. The lysate was further sonicated for $1 \mathrm{~min}$ to shear genomic DNA and then centrifuged at $15,000 \mathrm{rpm}$ at $4^{\circ} \mathrm{C}$ for $15 \mathrm{~min}$. Immunoprecipitation was performed using anti-Flag M2 Affinity $\mathrm{Gel}$ (Sigma) at $4^{\circ} \mathrm{C}$ for $2 \mathrm{~h}$ with constant rotation. The beads were washed with high-stringent RIPA buffer (RIPA buffer containing 
$1 \mathrm{M} \mathrm{NaCl}$ and $1 \mathrm{M}$ urea) four times, then with RIPA buffer twice, deproteinized by treating with Proteinase $\mathrm{K}$ at $60^{\circ} \mathrm{C}$ for $20 \mathrm{~min}$, and reverse crosslinked at $70^{\circ} \mathrm{C}$ for $45 \mathrm{~min}$. Coprecipitated RNA was extracted using TRI Reagent, treated with Recombinant DNase I, and reverse transcribed.

\section{Subcellular fractionation}

HEK293T cells from a 60-mm dish were collected and dispersed in $600 \mu \mathrm{L}$ of $1 \times$ PBS containing $0.1 \% \mathrm{NP}-40$ by gentle pipetting. Two hundred microliters of the resulting suspension was removed for the whole-cell fraction. The remaining suspension was centrifuged at $2200 \mathrm{rpm}$ at $4^{\circ} \mathrm{C}$ for $5 \mathrm{~min}$, and $200 \mu \mathrm{L}$ of the supernatant was taken as the cytoplasmic fraction. The nuclei were washed once with $1 \mathrm{ml}$ of $0.1 \% \mathrm{NP}-40 / 1 \times \mathrm{PBS}$ and resuspended in $200 \mu \mathrm{L}$ of $0.1 \% \mathrm{NP}-40 /$ $1 \times$ PBS. Each fraction was treated with $1 \mathrm{~mL}$ of TRI Reagent and subjected to RNA extraction.

\section{SUPPLEMENTAL MATERIAL}

Supplemental material is available for this article.

\section{ACKNOWLEDGMENTS}

We are grateful to Dr. V. Narry Kim (Seoul National University) for reagents and helpful discussion. We also thank the members of our laboratory for their critical comments on this manuscript. This work is supported by a grant from the Next-Generation BioGreen 21 Program (no. PJ01101803), Rural Development Administration, Republic of Korea.

Received October 27, 2016; accepted April 6, 2017.

\section{REFERENCES}

Agranat-Tamir L, Shomron N, Sperling J, Sperling R. 2014. Interplay between pre-mRNA splicing and microRNA biogenesis within the supraspliceosome. Nucleic Acids Res 42: 4640-4651.

Auyeung VC, Ulitsky I, McGeary SE, Bartel DP. 2013. Beyond secondary structure: primary-sequence determinants license pri-miRNA hairpins for processing. Cell 152: 844-858.

Ballarino M, Pagano F, Girardi E, Morlando M, Cacchiarelli D, Marchioni M, Proudfoot NJ, Bozzoni I. 2009. Coupled RNA processing and transcription of intergenic primary microRNAs. Mol Cell Biol 29: 5632-5638.

Bartel DP. 2009. MicroRNAs: target recognition and regulatory functions. Cell 136: 215-233.

Burger K, Gullerova M. 2015. Swiss army knives: non-canonical functions of nuclear Drosha and Dicer. Nat Rev Mol Cell Biol 16: 417-430.

Cheng TL, Wang Z, Liao Q, Zhu Y, Zhou WH, Xu W, Qiu Z. 2014. MeCP2 suppresses nuclear microRNA processing and dendritic growth by regulating the DGCR8/Drosha complex. Dev Cell 28: 547-560.

Chong MM, Zhang G, Cheloufi S, Neubert TA, Hannon GJ, Littman DR. 2010. Canonical and alternate functions of the microRNA biogenesis machinery. Genes Dev 24: 1951-1960.

Choudhury NR, de Lima Alves F, de Andrés-Aguayo L, Graf T, Cáceres JF, Rappsilber J, Michlewski G. 2013. Tissue-specific control of brain-enriched miR-7 biogenesis. Genes Dev 27: 24-38.

Cirera-Salinas D, Yu J, Bodak M, Ngondo RP, Herbert KM, Ciaudo C. 2017. Noncanonical function of DGCR8 controls mESC exit from pluripotency. J Cell Biol 216: 355-366.
Dai L, Chen K, Youngren B, Kulina J, Yang A, Guo Z, Li J, Yu P, Gu S. 2016. Cytoplasmic Drosha activity generated by alternative splicing. Nucleic Acids Res 44: 10454-10466.

Denli AM, Tops BB, Plasterk RH, Ketting RF, Hannon GJ. 2004. Processing of primary microRNAs by the Microprocessor complex. Nature 432: 231-235.

Di Carlo V, Grossi E, Laneve P, Morlando M, Dini Modigliani S, Ballarino M, Bozzoni I, Caffarelli E. 2013. TDP-43 regulates the microprocessor complex activity during in vitro neuronal differentiation. Mol Neurobiol 48: 952-963.

Dignam JD, Lebovitz RM, Roeder RG. 1983. Accurate transcription initiation by RNA polymerase II in a soluble extract from isolated mammalian nuclei. Nucleic Acids Res 11: 1475-1489.

Fang W, Bartel DP. 2015. The menu of features that define primary microRNAs and enable de novo design of microRNA genes. $\mathrm{Mol}$ Cell 60: 131-145.

Gregory RI, Yan KP, Amuthan G, Chendrimada T, Doratotaj B, Cooch N, Shiekhattar R. 2004. The Microprocessor complex mediates the genesis of microRNAs. Nature 432: 235-240.

Grishok A, Pasquinelli AE, Conte D, Li N, Parrish S, Ha I, Baillie DL, Fire A, Ruvkun G, Mello CC. 2001. Genes and mechanisms related to RNA interference regulate expression of the small temporal RNAs that control C. elegans developmental timing. Cell 106: 23-34.

Gromak N, Dienstbier M, Macias S, Plass M, Eyras E, Caceres JF, Proudfoot NJ. 2013. Drosha regulates gene expression independently of RNA cleavage function. Cell Rep 5: 1499-1510.

Ha M, Kim VN. 2014. Regulation of microRNA biogenesis. Nat Rev Mol Cell Biol 15: 509-524.

Hammond SM, Boettcher S, Caudy AA, Kobayashi R, Hannon GJ. 2001. Argonaute2, a link between genetic and biochemical analyses of RNAi. Science 293: 1146-1150.

Han J, Lee Y, Yeom KH, Kim YK, Jin H, Kim VN. 2004. The DroshaDGCR8 complex in primary microRNA processing. Genes Dev 18: 3016-3027.

Han J, Lee Y, Yeom KH, Nam JW, Heo I, Rhee JK, Sohn SY, Cho Y, Zhang BT, Kim VN. 2006. Molecular basis for the recognition of primary microRNAs by the Drosha-DGCR8 complex. Cell 125: 887-901.

Han J, Pedersen JS, Kwon SC, Belair CD, Kim YK, Yeom KH, Yang WY, Haussler D, Blelloch R, Kim VN. 2009. Posttranscriptional crossregulation between Drosha and DGCR8. Cell 136: 75-84.

Havens MA, Reich AA, Hastings ML. 2014. Drosha promotes splicing of a pre-microRNA-like alternative exon. PLoS Genet 10: e1004312.

Heras SR, Macias S, Plass M, Fernandez N, Cano D, Eyras E, GarciaPerez JL, Caceres JF. 2013. The Microprocessor controls the activity of mammalian retrotransposons. Nat Struct Mol Biol 20: 1173-1181.

Hutvagner G, McLachlan J, Pasquinelli AE, Balint E, Tuschl T, Zamore PD. 2001. A cellular function for the RNA-interference enzyme Dicer in the maturation of the let-7 small temporal RNA. Science 293: 834-838.

Irimia $M$, Weatheritt RJ, Ellis JD, Parikshak NN, GonatopoulosPournatzis T, Babor M, Quesnel-Vallieres M, Tapial J, Raj B, O'Hanlon D, et al. 2014. A highly conserved program of neuronal microexons is misregulated in autistic brains. Cell 159: 1511-1523.

Janas MM, Khaled M, Schubert S, Bernstein JG, Golan D, Veguilla RA, Fisher DE, Shomron N, Levy C, Novina CD. 2011. Feed-forward microprocessing and splicing activities at a microRNA-containing intron. PLoS Genet 7: e1002330.

Jin Y, Yang Y, Zhang P. 2011. New insights into RNA secondary structure in the alternative splicing of pre-mRNAs. RNA Biol 8: 450-457.

Johanson TM, Keown AA, Cmero M, Yeo JH, Kumar A, Lew AM, Zhan Y, Chong MM. 2015. Drosha controls dendritic cell development by cleaving messenger RNAs encoding inhibitors of myelopoiesis. Nat Immunol 16: 1134-1141.

Kadener S, Rodriguez J, Abruzzi KC, Khodor YL, Sugino K, Marr MT II, Nelson S, Rosbash M. 2009. Genome-wide identification of targets of the drosha-pasha/DGCR8 complex. RNA 15: 537-545.

Karginov FV, Cheloufi S, Chong MM, Stark A, Smith AD, Hannon GJ. 2010. Diverse endonucleolytic cleavage sites in the mammalian 
transcriptome depend upon microRNAs, Drosha, and additional nucleases. Mol Cell 38: 781-788.

Kataoka N, Fujita M, Ohno M. 2009. Functional association of the Microprocessor complex with the spliceosome. Mol Cell Biol 29: 3243-3254.

Kawahara Y, Mieda-Sato A. 2012. TDP-43 promotes microRNA biogenesis as a component of the Drosha and Dicer complexes. Proc Natl Acad Sci 109: 3347-3352.

Kim YK, Kim VN. 2007. Processing of intronic microRNAs. EMBO J 26: 775-783.

Kim YK, Kim B, Kim VN. 2016. Re-evaluation of the roles of DROSHA, Export in 5, and DICER in microRNA biogenesis. Proc Natl Acad Sci 113: E1881-1889.

Knuckles P, Vogt MA, Lugert S, Milo M, Chong MM, Hautbergue GM, Wilson SA, Littman DR, Taylor V. 2012. Drosha regulates neurogenesis by controlling neurogenin 2 expression independent of microRNAs. Nat Neurosci 15: 962-969.

Kwon SC, Nguyen TA, Choi YG, Jo MH, Hohng S, Kim VN, Woo JS. 2016. Structure of Human DROSHA. Cell 164: 81-90.

Lee Y, Kim VN. 2007. In vitro and in vivo assays for the activity of Drosha complex. Methods Enzymol 427: 89-106.

Lee Y, Ahn C, Han J, Choi H, Kim J, Yim J, Lee J, Provost P, Radmark O, Kim S, et al. 2003. The nuclear RNase III Drosha initiates microRNA processing. Nature 425: 415-419.

Lin YT, Sullivan CS. 2011. Expanding the role of Drosha to the regulation of viral gene expression. Proc Natl Acad Sci 108: 11229-11234.

Link S, Grund SE, Diederichs S. 2016. Alternative splicing affects the subcellular localization of Drosha. Nucleic Acids Res 44: 5330-5343.

Long JC, Caceres JF. 2009. The SR protein family of splicing factors: master regulators of gene expression. Biochem J 417: 15-27.

Lujambio A, Lowe SW. 2012. The microcosmos of cancer. Nature 482: 347-355.

Macias S, Plass M, Stajuda A, Michlewski G, Eyras E, Caceres JF. 2012. DGCR8 HITS-CLIP reveals novel functions for the Microprocessor. Nat Struct Mol Biol 19: 760-766.

Marinaro F, Marzi MJ, Hoffmann N, Amin H, Pelizzoli R, Niola F, Nicassio F, De Pietri Tonelli D. 2017. MicroRNA-independent functions of DGCR8 are essential for neocortical development and TBR1 expression. EMBO Rep 18: 603-618.

Mattioli C, Pianigiani G, Pagani F. 2013. A competitive regulatory mechanism discriminates between juxtaposed splice sites and pri-miRNA structures. Nucleic Acids Res 41: 8680-8691.

McManus CJ, Graveley BR. 2011. RNA structure and the mechanisms of alternative splicing. Curr Opin Genet Dev 21: 373-379.

Melamed Z, Levy A, Ashwal-Fluss R, Lev-Maor G, Mekahel K, Atias N, Gilad S, Sharan R, Levy C, Kadener S, et al. 2013. Alternative splicing regulates biogenesis of miRNAs located across exon-intron junctions. Mol Cell 50: 869-881.

Michlewski G, Caceres JF. 2010. RNase-assisted RNA chromatography. RNA 16: 1673-1678.

Morlando M, Ballarino M, Gromak N, Pagano F, Bozzoni I, Proudfoot NJ. 2008. Primary microRNA transcripts are processed co-transcriptionally. Nat Struct Mol Biol 15: 902-909.
Mourelatos Z, Dostie J, Paushkin S, Sharma A, Charroux B, Abel L, Rappsilber J, Mann M, Dreyfuss G. 2002. miRNPs: a novel class of ribonucleoproteins containing numerous microRNAs. Genes Dev 16: 720-728.

Nguyen TA, Jo MH, Choi YG, Park J, Kwon SC, Hohng S, Kim VN, Woo JS. 2015. Functional anatomy of the human microprocessor. Cell 161: 1374-1387.

Nilsen TW. 2014. Detecting RNA-RNA interactions using psoralen derivatives. Cold Spring Harb Protoc 2014: 996-1000.

Niranjanakumari S, Lasda E, Brazas R, Garcia-Blanco MA. 2002. Reversible cross-linking combined with immunoprecipitation to study RNA-protein interactions in vivo. Methods 26: 182-190.

Pawlicki JM, Steitz JA. 2010. Nuclear networking fashions pre-messenger RNA and primary microRNA transcripts for function. Trends Cell Biol 20: 52-61.

Piriyapongsa J, Marino-Ramirez L, Jordan IK. 2007. Origin and evolution of human microRNAs from transposable elements. Genetics 176: 1323-1337.

Qin S, Jin P, Zhou X, Chen L, Ma F. 2015. The role of transposable elements in the origin and evolution of microRNAs in human. PLoS One 10: $\mathrm{e} 0131365$.

Roberts JT, Cardin SE, Borchert GM. 2014. Burgeoning evidence indicates that microRNAs were initially formed from transposable element sequences. Mob Genet Elements 4: e29255.

Shepard PJ, Hertel KJ. 2009. The SR protein family. Genome Biol 10: 242.

Shin C, Nam JW, Farh KK, Chiang HR, Shkumatava A, Bartel DP. 2010. Expanding the microRNA targeting code: functional sites with centered pairing. Mol Cell 38: 789-802.

Tang X, Zhang Y, Tucker L, Ramratnam B. 2010. Phosphorylation of the RNase III enzyme Drosha at Serine300 or Serine302 is required for its nuclear localization. Nucleic Acids Res 38: 6610-6619.

Tang X, Li M, Tucker L, Ramratnam B. 2011. Glycogen synthase kinase $3 \beta$ (GSK3 $\beta$ ) phosphorylates the RNAase III enzyme Drosha at S300 and S302. PLoS One 6: e20391.

Tang X, Wen S, Zheng D, Tucker L, Cao L, Pantazatos D, Moss SF, Ramratnam B. 2013. Acetylation of Drosha on the N-terminus inhibits its degradation by ubiquitination. PLoS One 8: e72503.

Triboulet R, Chang HM, Lapierre RJ, Gregory RI. 2009. Post-transcriptional control of DGCR8 expression by the Microprocessor. RNA 15: $1005-1011$.

Yang Q, Li W, She H, Dou J, Duong DM, Du Y, Yang SH, Seyfried NT, $\mathrm{Fu} \mathrm{H}, \mathrm{Gao}$ G, et al. 2015. Stress induces p38 MAPK-mediated phosphorylation and inhibition of Drosha-dependent cell survival. Mol Cell 57: 721-734.

Yuan Z, Sun X, Jiang D, Ding Y, Lu Z, Gong L, Liu H, Xie J. 2010. Origin and evolution of a placental-specific microRNA family in the human genome. BMC Evol Biol 10: 346.

Zeng Y, Yi R, Cullen BR. 2005. Recognition and cleavage of primary microRNA precursors by the nuclear processing enzyme Drosha. EMBO J 24: 138-148.

Zuker M. 2003. Mfold web server for nucleic acid folding and hybridization prediction. Nucleic Acids Res 31: 3406-3415. 

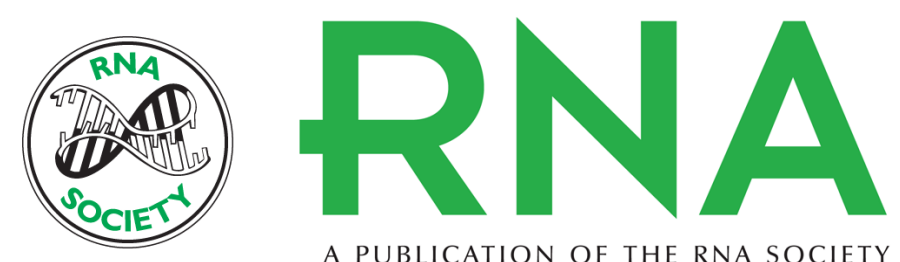

A PUBLICATION OF THE RNA SOCIETY

\section{DROSHA targets its own transcript to modulate alternative splicing}

Dooyoung Lee, Jin-Wu Nam and Chanseok Shin

RNA 2017 23: 1035-1047 originally published online April 11, 2017

Access the most recent version at doi:10.1261/rna.059808.116

Supplemental Material

References

Creative Commons License

Email Alerting Service
http://rnajournal.cshlp.org/content/suppl/2017/04/11/rna.059808.116.DC1

This article cites 68 articles, 20 of which can be accessed free at: http://rnajournal.cshlp.org/content/23/7/1035.full.html\#ref-list-1

This article is distributed exclusively by the RNA Society for the first 12 months after the full-issue publication date (see http://rnajournal.cshlp.org/site/misc/terms.xhtml). After 12 months, it is available under a Creative Commons License (Attribution-NonCommercial 4.0 International), as described at http://creativecommons.org/licenses/by-nc/4.0/.

Receive free email alerts when new articles cite this article - sign up in the box at the top right corner of the article or click here.

To subscribe to $R N A$ go to:

http://rnajournal.cshlp.org/subscriptions 